“ (C) 2018 IEEE. Personal use of this material is permitted. Permission from IEEE must be obtained for all other uses, in any current or future media, including

reprinting/republishing this material for advertising or promotional purposes, creating new collective works, for resale or redistribution to servers or lists, or reuse of any copyrighted component of this work in other works." 


\title{
A Compact Three-Port DC-DC Converter for Integrated PV-Battery System
}

\author{
Mohammad Al-Soeidat*, ${ }^{*}$ Student Member, IEEE, Habes Khawaldeh*, Hamzeh Aljarajreh*, Dylan Lu* \\ Senior Member, IEEE \\ * School of Electrical and Data Engineering, University of Technology Sydney, Sydney, Australia \\ ${ }^{\dagger}$ Department of Electrical Engineering, Al-Hussein Bin Talal University, Maan, Jordan \\ Email: ${ }^{\dagger}$ Mohammad.r.al-soeidat@student.uts.edu.au
}

\begin{abstract}
In this paper, a new non-isolated three-port DCDC converter (NITPC) to integrate a battery storage with a PV module is proposed. The intermittency of renewable energy and the unpredictable load demand are eliminated by firming a backup battery with the PV module to supply extra power when it is required. The proposed converter is reconfigurable and able to operate as a conventional boost converter, a buck-boost converter or a forward converter in different modes to support several power flow combinations and achieve power conditioning and regulation among the PV module, battery and an output port simultaneously. Nevertheless, the converter only consists of two switches, one coupled inductor, one diode and two capacitors. Thus, the system size and number of components are reduced compared with the traditional DC-DC converters. High output regulated voltage is achieved by using a coupled inductor and by combining the PV module and the battery in series. Simulation and experiment are carried out to verify the proposed circuit.

Index Terms - three-port converter, photovoltaic, battery, Single-input Single-output (SISO), Single-input dual-output (SIDO), Dual-input single-output (SIDO), Dual-input dual-output (DIDO), maximum power point algorithm (MPPT), renewable energy.
\end{abstract}

\section{INTRODUCTION}

There is an increasing demand for renewable energy sources recently due to their economical viability, high electricity prices and green initiatives. Solar energy, in particular, is one of the most useful sources of sustainable energy in many industrial and residential applications. However, the intermittency of solar power negatively affects the efficiency, durability, power handling capability, and reliability of the power system. To mitigate such problem, a power electronic converter is used to interface the photovoltaic (PV) module with another power source with the load. This power converter is used to track the maximum power point (MPP) of the solar panel, manage battery charging and regulate output voltage [1], [2].

Traditionally, a single DC-DC power converter with two ports is used to connect only one energy source with the load [3], [4]. To use more than one input power source or storage element, there is a need to use multiple power converters. In addition to reduced efficiency, the cost, the number of components and the complexity of the system increase [5], [6].
In recent years, several multiport converters (MPC), illustrated in Fig. 1, have been proposed to connect the renewable energy source with the storage system. MPC has several advantages including its low cost, mass and component count. It increases the system reliability and uses a centralized control, resulting in less communication delay and errors. Moreover, using multi-port converter will offer multi-input multi-output (MIMO) feature, so the power could flow between two ports

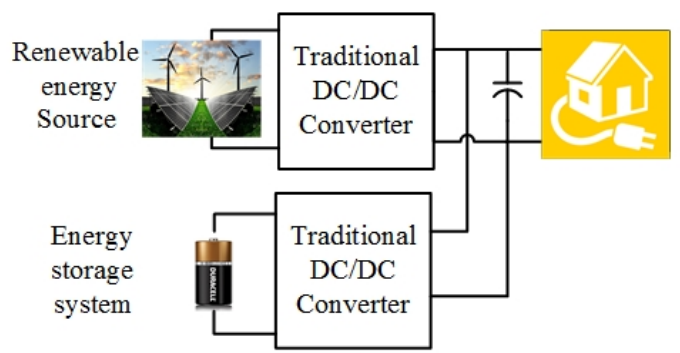

(a)

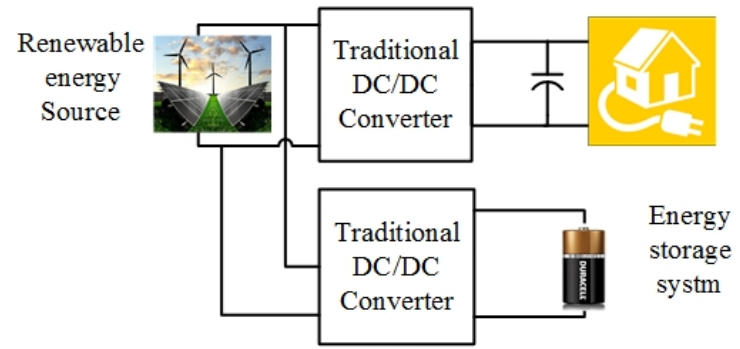

(b)

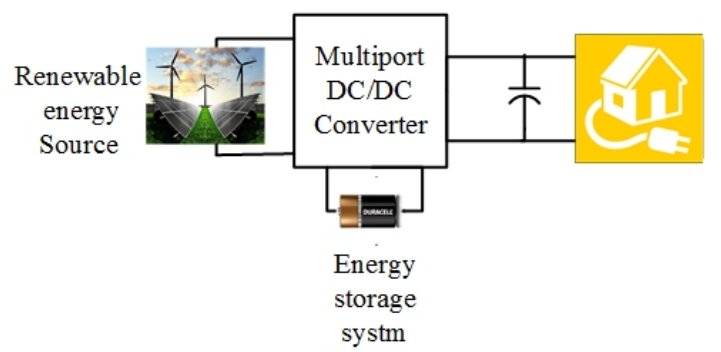

(c)

Fig. 1. Traditional MPC: a) Tradition DISO, b) Tradition SIDO. 
only as a single-input single-output (SISO), or between three ports simultaneously, which is known as single-input dualoutput (SIDO) or dual-input single-output (DISO).

MPC can be classified into three groups namely: nonisolated, partly isolated and isolated converter. The isolated converter uses a high-frequency transformer to achieve a high voltage regulation ratio and the galvanic isolation feature [5], [7]. It can also easily achieve zero voltage switching (ZVS) by using phase shift control for all switches in the full bridge converter. Nevertheless, the isolated converter requires a high number of switches and associated gate driver circuits. They may lead to more switching losses. Also, transformerbased topology would require significant effort in dealing with leakage energy and more complicated control strategy to direct power flow among different ports [4], [7]-[9]. In some applications, when the high voltage regulation ratio is required, and the galvanic isolation feature is not necessary between the all ports, partly-isolated converter is a better option [10]-[12]. Non-isolated converter has some advantages over other categories such as higher efficiency, smaller volume, less number of components, and easier to implement and control. Authors in [1], [5], [13], [14] have proposed nonisolated converters. Although the number of the switches is lowered, the voltage gain is limited. In [15] a novel highvoltage nonisolated converter has been proposed by using a coupled inductor with a different turns ratio. Meanwhile, three power switches and five diode are used to implement the circuit, but the component count is still high.

In this paper, a new non-isolated three-port-converter is proposed. By adding one switch and a couple inductor to the circuit proposed in [13], the intermittency of the renewable energy and any unpredictable change in demand will be eliminated by having better control for the battery charging and MPPT simultaneously. Also, the coupled inductor is used to extend the output voltage to a higher level. The paper is organized as follows: In Section II, the proposed circuit is introduced and the operation mode is analyzed. In Section III, the system setup is discussed. In Section IV. The results are explained, followed by the conclusion in Section V.

\section{OPERATION PRINCIPLE}

\section{A. Proposed Circuit}

The proposed three-port converter, shown in Fig. 2, has three ports namely, a unidirectional input port, a bi-directional battery port and an output port. The circuit has only two power switches, one diode, two capacitors, and one coupled inductor. $V_{P V}$ is the input port, it is connected to the main source of power which is the photovoltaic module. The battery port $V_{B}$ is connected to battery storage system so that it can be used either to provide a high voltage gain due to its series configuration with the input port or supply more power to the output in order to solve the intermittency issue. Meanwhile, the proposed circuit is able to achieve MPPT, manage battery charging/discharging and regulate output voltage. The coupled inductor formed by $L_{P}$ and $L_{S}$ and its turn ratio $N_{1} / N_{2}$ is

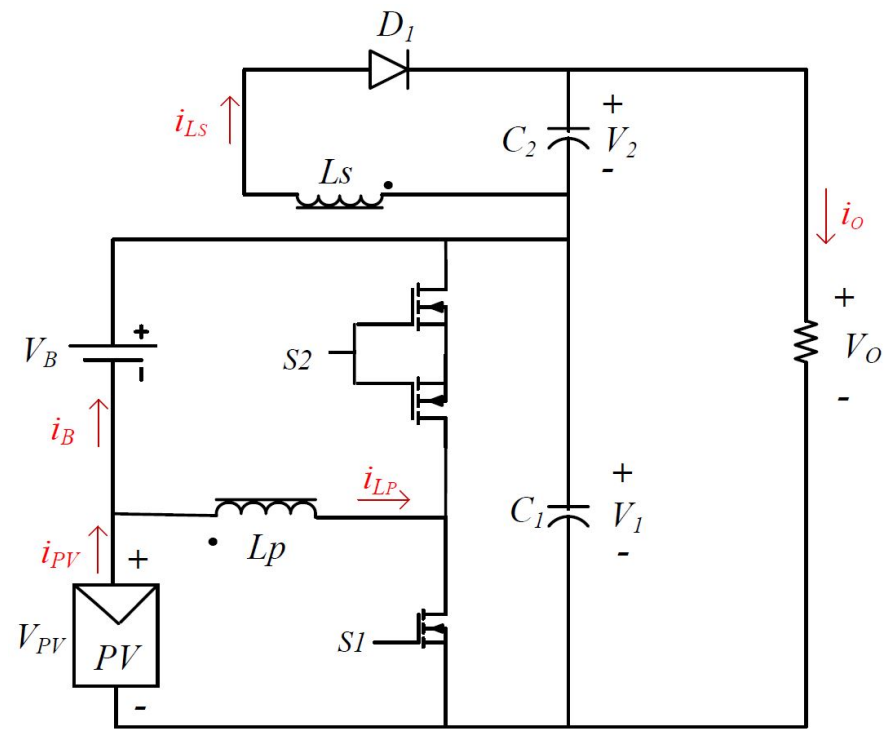

Fig. 2. proposed circuit.

used to provide a higher voltage boost. The output capacitors $C_{1}$ and $C_{2}$ are large enough to smooth the output voltage.

\section{B. Operation Modes}

The power flow among the ports in the proposed three-port converter has six potential operation modes. These modes are listed below:

1) Single-input single-output (SISO) PV-battery mode: this mode is active when the PV module stores power in a battery no-load unloading condition, as depicted in Fig. 3(a).

2) Single-input single-output (SISO) PV-load mode: this mode is active when the PV module supplies power the load assuming the battery is not connected or nonoperational, as depicted in Fig. 3(b).

3) Single-input single-output (SISO) battery-load mode: This mode is active only when the battery supplies power to the load. In this mode, the PV module is either shaded or not supplying power at night time, as depicted in Fig. 3(c).

4) Dual-input single-output (DISO) mode: this mode is active when the PV module and the battery supply power simultaneously to the load, as depicted in Fig. 3(d).

5) Single-input dual-output (SIDO): this mode is active when the PV module supplies power to the load. The unused generated power from the PV is stored at the battery as depicted in Fig. 3(e).

6) Dual-input dual-output (DIDO): this mode is active when the PV supplies power to the load and the battery is charged and discharged by approximately same amount of power as depicted in Fig. 3(f).

\section{Steady-State Analysis}

- (SISO) PV-battery mode: in this mode, $S_{1}$ and $S_{2}$ are operating in a complementary mode. The power gener- 
ated by the PV module charges the battery to be used later. The combination of $V_{P V}, L_{P}, S_{1}, S_{2}$ and $V_{b}$ is considered as a buck-boost converter. Thus, the battery charges effectively. Fig. 4(a) shows the current bath flow

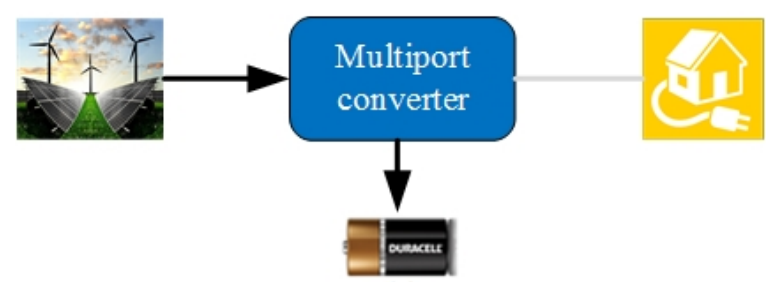

(a)

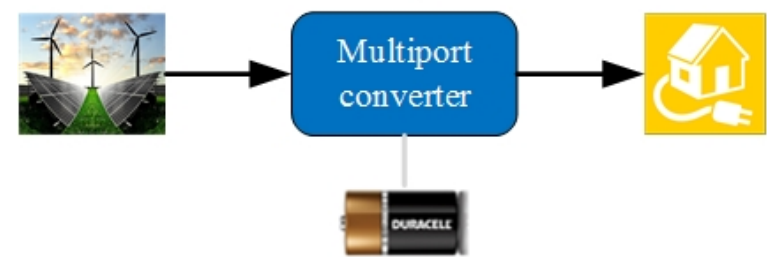

(b)

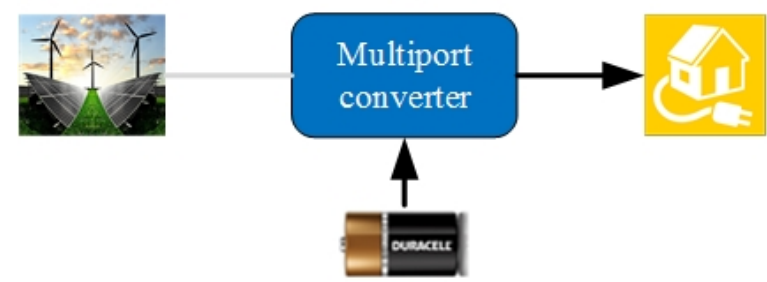

(c)

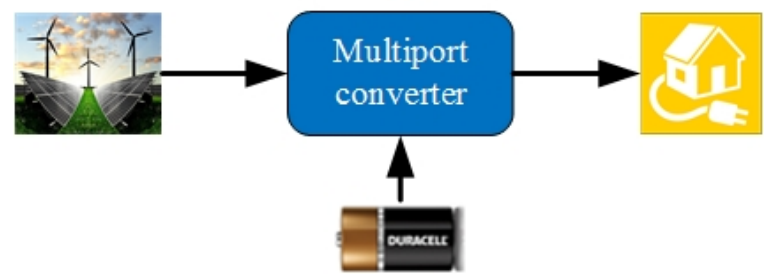

(d)
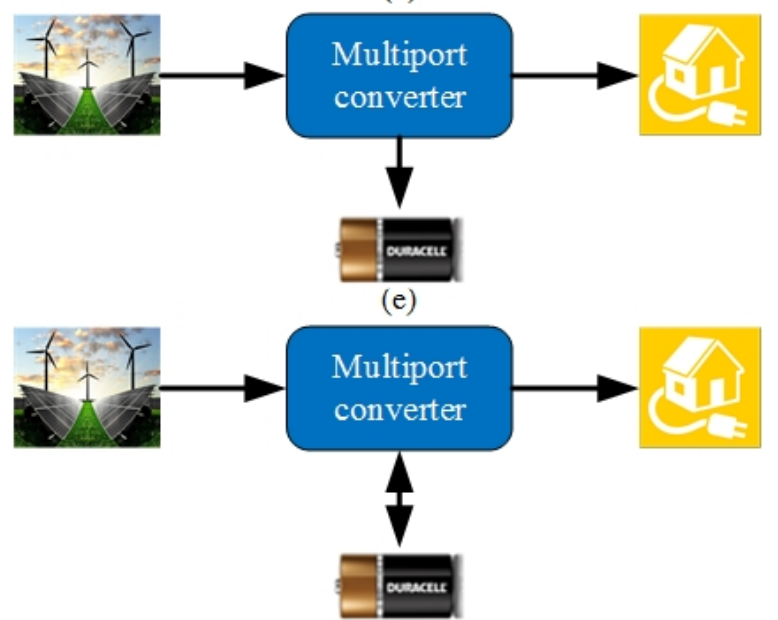

(f)

Fig. 3. Power flow TPC and operation modes: (a) (SISO) PV-battery mode, (b) (SISO) PV-load mode, (c) (SISO) battery-load mode, (d) DISO mode, (e) SIDO mode, (f) DIDO mode. for the proposed converter.

- (SISO) battery-Load mode: in this mode, only two ports are active, the battery and the output port. The combination of $V_{P V}, L_{P}, L_{S}, S_{1}, D_{1}, C_{2}$ and $V_{2}$ is considered as a forward converter, and the current path flow is shown in Fig. 4(c).

- (SIDO), (DISO) and (DIDO) modes: in these three modes, the following three assumptions are made: the combination of $V_{P V}, L_{P}, L_{S}, S_{1}, D_{1}, C_{2}$ and $V_{2}$ is considered as a Flyback converter, the combination of $V_{P V}, L_{P}, S_{1}, S_{2}$ and $V_{b}$ is considered as a buck-boost converter and the combination of $V_{P V}, L_{P}, S_{1}, S_{2}, C_{1}$ and $V_{1}$ is considered as a boost converter. All ports, in these modes, are active, the only difference is the current flow of the battery port.

If the input power is less than the output power, the current will be drawn from the PV module and the battery to supply the load. Thus, and the converter will be operating at Dual Input Single Output (DISO) mode. The current will flow the path shown in Fig. 4(d).

If the input power is greater than the output power, some power will be stored in the battery; then, the converter will operate at Single input Dual output (SIDO) mode. As it is illustrated from the current path flow, Fig. 4(e), when the switch $S_{1}$ is closed and $S_{2}$ is opened, the inductor and the battery begins charging by the PV module. Then, when $S_{2}$ is closed and $S_{1}$ is opened, the inductor starts discharging, and the current will continue in the same direction, charging the battery and transferring the power to the output port by the coupled inductor.

On the other hand, Dual Input Dual Output (DIDO) mode, Fig. 4 (e) and Fig. 4 (f), is a balanced mode between SIDO and DISO modes and it is the most dominant mode. The key waveforme for this mode is shown in Fig. 5, and the switching modes fot DIDO are describded as follow: Switching mode I [ $t_{0}<t<t_{1}$ ]: in this switching mode, switch $S_{1}$ is turned ON while $S_{2}$ is turned OFF. The primary inductor, $L_{P}$, starts to charge by the input source $V_{P V} . D_{1}$ is revised bias due to the polarity of the secondary winding of the coupled indutor. The battery current starts to decrease until it reaches to zero at $t=t_{1}$ then this mode ends.

Switching mode II [ $t_{1}<t<t_{2}$ ]: in this switching mode, switch $S_{1}$ remains ON and $S_{2}$ is turned OFF. the primary inductor keep chargeing and $D_{1}$ keep reviresed bias. Nevertheless, the battery starts dischrging and this mode ends at $t=t_{2}$.

Switching mode III $\left[t_{2}<t<t_{3}\right.$ ]: in this mode, switches $S_{1}$ is turned OFF while $S_{2}$ is ON. The primary inductor starts to discharge and its energy flies to the secondary inductor and the battery at the same time. This mode ends at $t=t_{3}$.

Switching mode IV [ $t_{3}<t<t_{4}$ ]: in this switching mode, switch $S_{1}$ remains OFF and $S_{2}$ ON. The battery starts to discharge in order to supply more power to the load. This mode ends at $t=t_{4}$. 


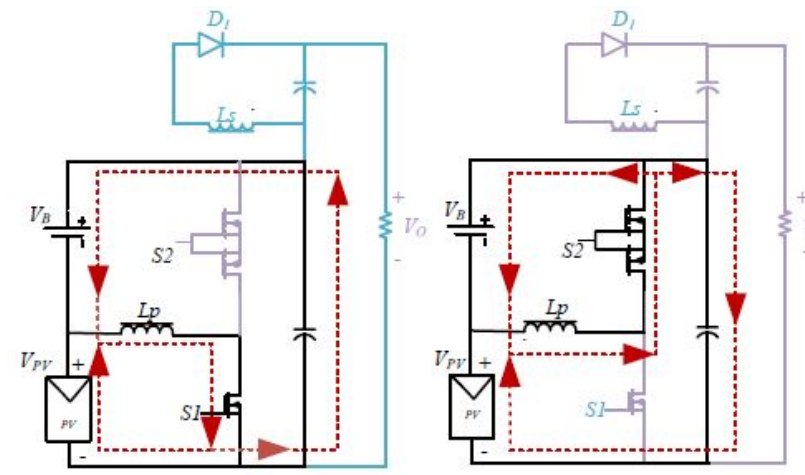

a)

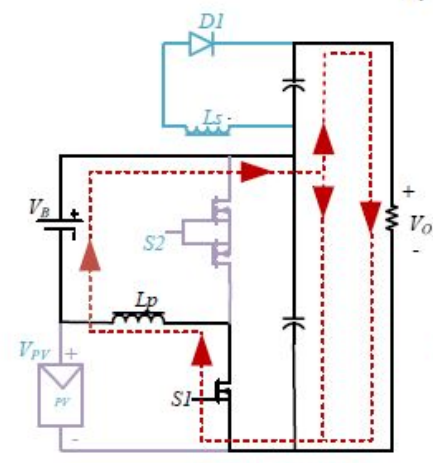

c)
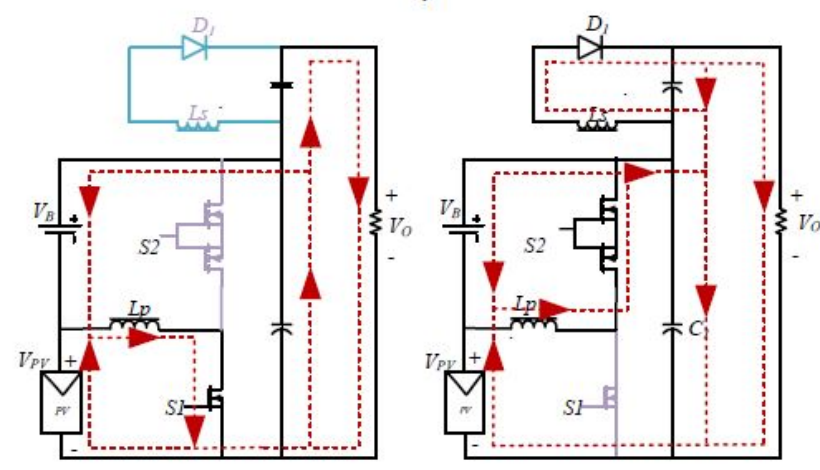

e)

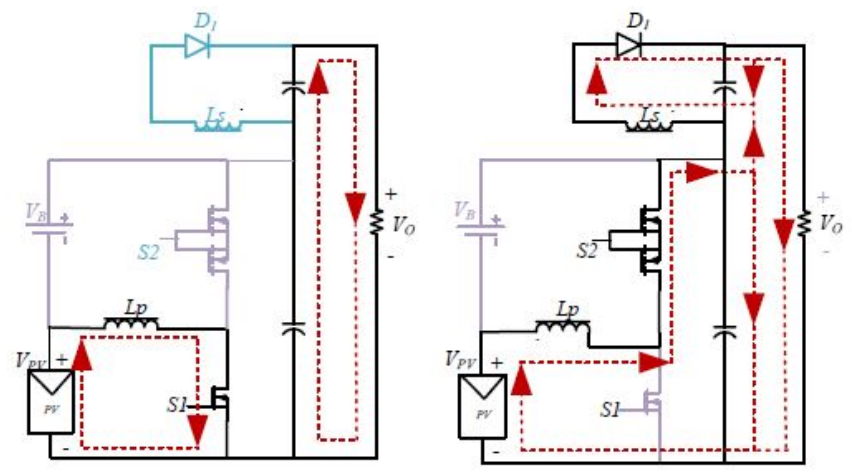

b)
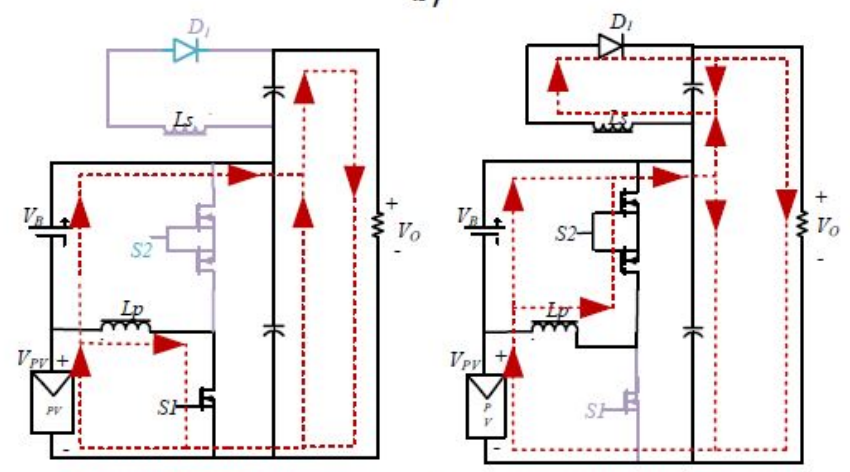

d)
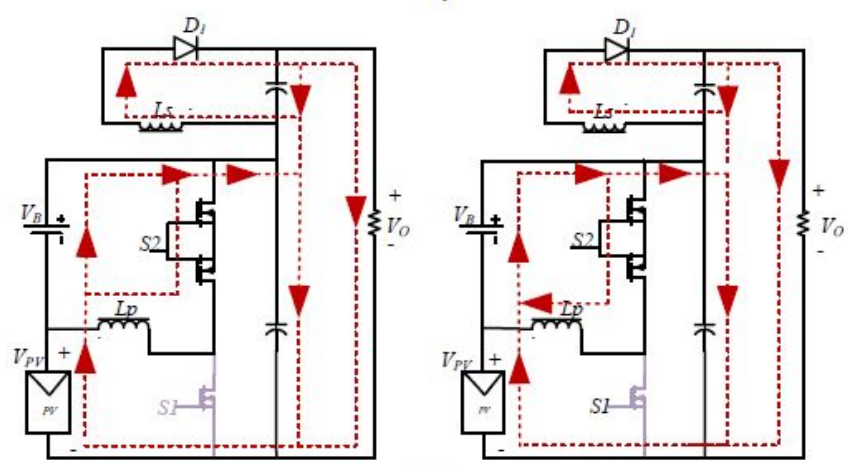

f)

Fig. 4. Power flow TPC and operation modes:(a) (SISO) PV-battery mode, (b) (SISO) PV-load mode, (c) (SISO) battery-load mode, (d) DISO mode, (e) SIDO mode, (e\&f) DIDO mode.

Switching mode $\mathbf{V}\left[t_{4}<t<t_{0}\right]$ : in this switching mode, the current direction on the primary inductor will be flipped due to the direction of the current in the battery and the secondary inductor that is coupled with the primary, this mode ends at $t=t_{0}$.

\section{EXPERIMENTAL VERIFICATIONS}

In order to verify the performance of the proposed converter, initially, the proposed circuit simulated using LTspice/SwitcherCAD III. Then, after confirming the operation modes and the power flow for all modes, the laboratory prototype shown in Fig. 7 is built and tested under different testing conditions. The schematic diagram of the fabricated

TABLE I

DETAILS OF COMPONENTS.

\begin{tabular}{ll}
\hline \hline Component & Model/Value \\
\hline Digital controller & TMS320F28335 \\
MOSFET & IRF540N \\
MOSFET Driver for S1 & TC4426 \\
MOSFET Driver for S2 & IR2184PBF \\
D1 & MBR2035CT \\
Coupled inductor core & RM14/I-3C95 \\
$N_{2} / N_{1}$ & $1 / 2$ \\
$L_{1}$ & $100 \mathrm{uH}$ \\
$L_{2}$ & $400 \mathrm{uH}$ \\
$C_{1} \& C_{2}$ & $470 \mathrm{uF}$ \\
\hline \hline
\end{tabular}



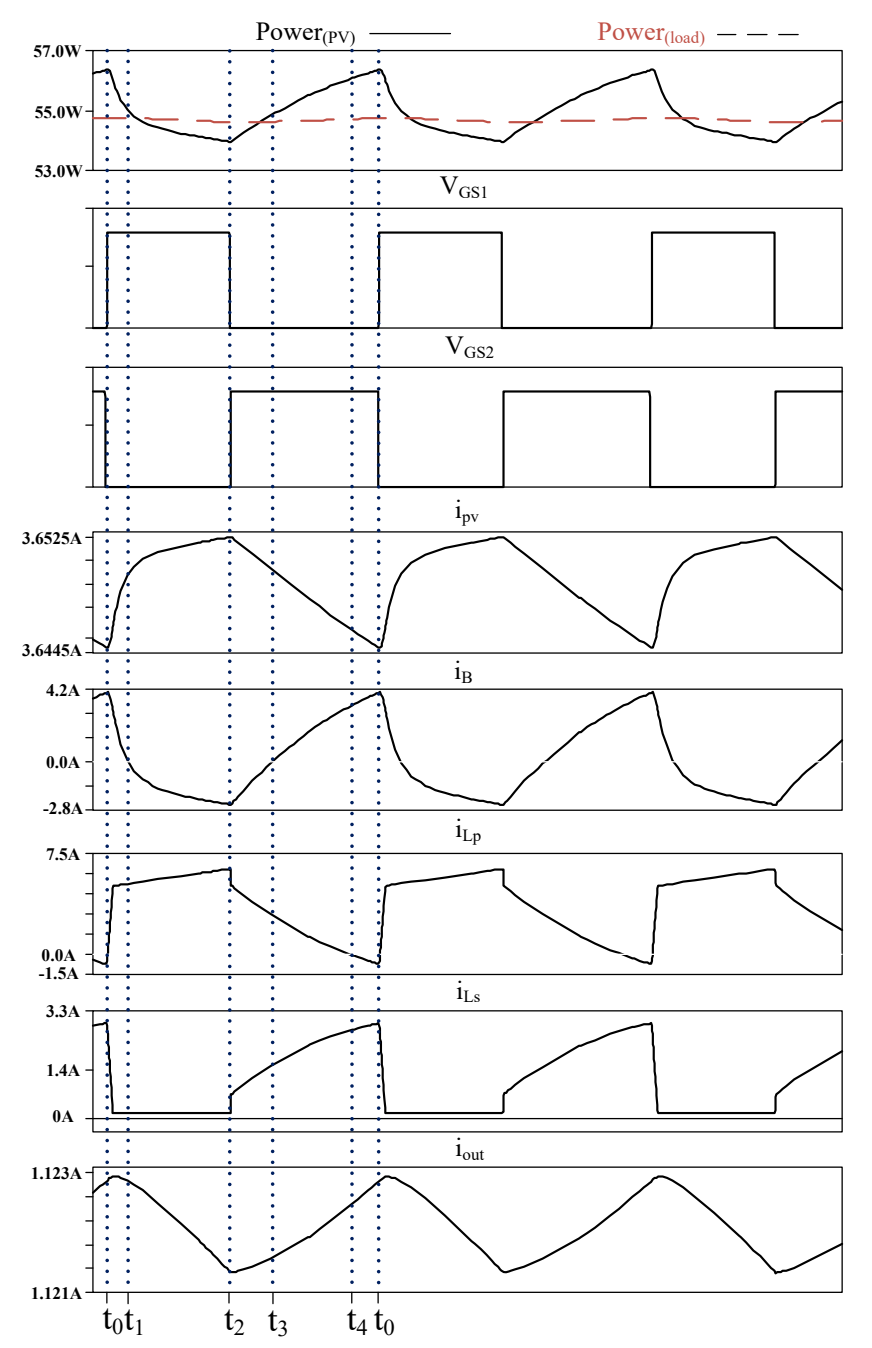

Fig. 5. Key switching waveforms for DIDO mode (Mode e and $f$ in Fig. 3).

PCB shows in Fig. 6, and the components used are listed in Table I.

A $60 \mathrm{~W}$ solar panel is used as a main source of power, and it is connected to the input port. The solar radiation emulated by using a set of artificial lights (500 w halogen light). A $12 \mathrm{~V}$, 12Ah lead-acid battery is connected to the unidirectional port (battery port) to store the unused power and to supply more power to the load when required to reduce the intermittency effects. The output port is connected to a programmable DC electronic load to mimic the change in the power consumption.

A PI controller with $\mathrm{P} \& \mathrm{O}$ algorithm is used to track the MPP and regulate the output voltage respectively. A Texas Instrument DSP, TMS320F28335 is used to control the power flow and generate PWM signals to drive the switches. The switching frequency is set at $50 \mathrm{kHz}$.

\section{EXPERIMENTAL RESULTS}

The voltage waveform for the dominant mode, DIDO, is shown in Fig. 8. The photovoltaic panel is operated at 18.5

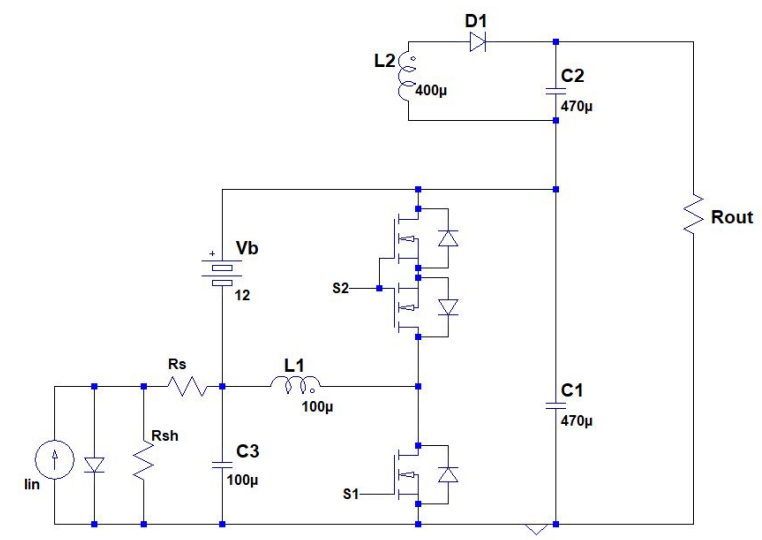

Fig. 6. schematic diagram.

$\mathrm{V}$ which is the voltage at the MPP while the output voltage regulated around $48 \mathrm{~V}$. Nevertheless, the battery is charging and discharging by each cycle. The average battery current is zero. That means the battery charging and discharging by the same amount of power. Also it helps to boost the output voltage up due to the circuit combination between the PV module and the battery.

The efficiency of the proposed converter is varied between 97.02\% for SISO PV-load mode, 93.09\% for SISO PV-battery mode, $92.45 \%$ for SISO battery-load mode, $95.49 \%$ for DISO, 97.26\% for SIDO and $95.04 \%$ for DIDO. The proposed converter can achieve MPP by using Perturb and Observe $(\mathrm{P} \& \mathrm{O})$ algorithm and regular the output voltage around 48 $\mathrm{V}$ for the all modes at a lower duty cycle. The operation duty cycle for the main switch changing between $32 \%$ and $47 \%$.

\section{CONCLUSION}

A new non-isolated multiport converter is proposed and experimentally verified to integrate a backup battery with a PV module. A converter has an input unidirectional port for the PV module, a bidirectional port for a backup battery and

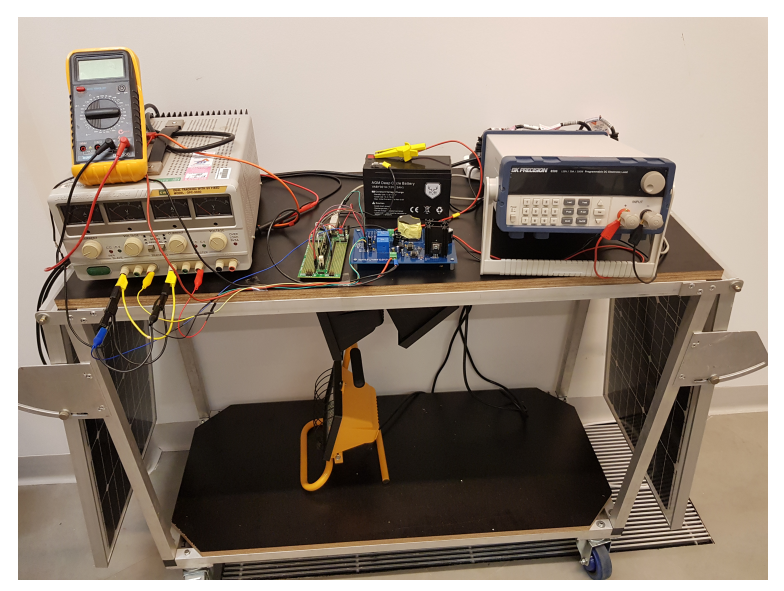

Fig. 7. Laboratory prototype. 


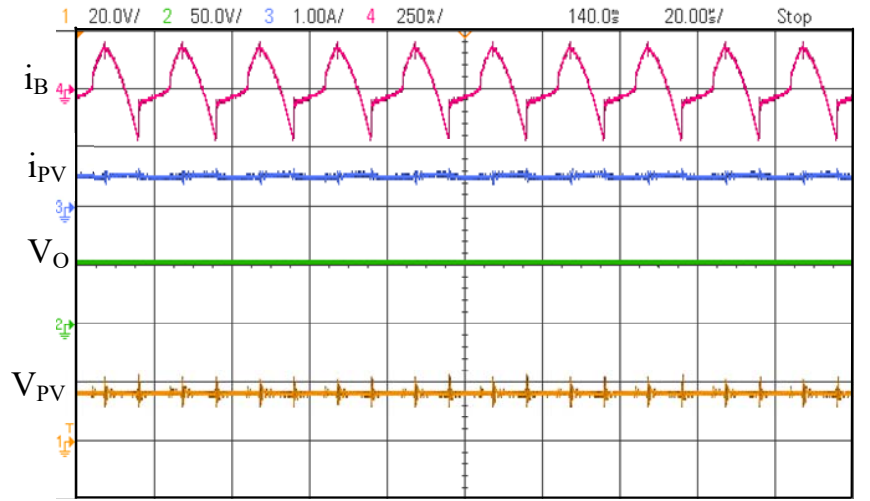

Fig. 8. Experiment result, DIDO mode. Time base: $20 \mu \mathrm{s} . V_{P V}: 10 \mathrm{~V} / \mathrm{div}$. $V_{P V}: 10 \mathrm{~V} /$ div. $V_{P V}: 10 \mathrm{~V} /$ div. $V_{P V}: 10 \mathrm{~V} /$ div.

an output port. The converter can provide a high regulated output voltage by connecting the renewable energy source in series with the battery, and by using a coupled inductor. In addition, the proposed MPC can easily solve the problem of intermittency by using simple control method. The highest efficiency for the proposed converter equals $97.26 \%$ while the lowest equals $92.45 \%$.

\section{ACKNOWLEDGMENT}

The first author gratefully acknowledge the Scholarship received towards his $\mathrm{PhD}$ from the Al-Hussein Bin Talal University (Ahu/4/2047). This research was funded (partially or fully) by the Australian Government through the Australian Research Council (Discovery Project No. DP180100129).

\section{REFERENCES}

[1] L. An and D. D. Lu, "Design of a single-switch dc/dc converter for a pv-battery-powered pump system with pfm+pwm control," IEEE Transactions on Industrial Electronics, vol. 62, no. 2, pp. 910-921, Feb 2015.

[2] X. Sun, Y. Shen, W. Li, and H. Wu, "A pwm and pfm hybrid modulated three-port converter for a standalone pv/battery power system," IEEE Journal of Emerging and Selected Topics in Power Electronics, vol. 3, no. 4, pp. 984-1000, Dec 2015.

[3] B. G. Dobbs and P. L. Chapman, "A multiple-input dc-dc converter topology," IEEE Power Electronics Letters, vol. 1, no. 1, pp. 6-9, March 2003.

[4] H. Tao, A. Kotsopoulos, J. L. Duarte, and M. A. M. Hendrix, "Family of multiport bidirectional dc-dc converters," IEE Proceedings - Electric Power Applications, vol. 153, no. 3, pp. 451-458, May 2006.

[5] Z. Zhou, H. Wu, X. Ma, and Y. Xing, "A non-isolated three-port converter for stand-alone renewable power system," in IECON 2012 - 38th Annual Conference on IEEE Industrial Electronics Society, Oct 2012, pp. 3352-3357.

[6] H. Wu, Y. Xing, Y. Xia, and K. Sun, "A family of non-isolated three-port converters for stand-alone renewable power system," in IECON 2011 37th Annual Conference of the IEEE Industrial Electronics Society, Nov 2011, pp. 1030-1035.

[7] H. Tao, A. Kotsopoulos, J. L. Duarte, and M. A. M. Hendrix, "Triplehalf-bridge bidirectional converter controlled by phase shift and pwm," in Twenty-First Annual IEEE Applied Power Electronics Conference and Exposition, 2006. APEC '06., March 2006, pp. 7 pp.-.

[8] H. Tao, J. L. Duarte, and M. A. M. Hendrix, "Three-port triplehalf-bridge bidirectional converter with zero-voltage switching," IEEE Transactions on Power Electronics, vol. 23, no. 2, pp. 782-792, March 2008.
[9] M. Michon, J. L. Duarte, M. Hendrix, and M. G. Simoes, "A threeport bi-directional converter for hybrid fuel cell systems," in 2004 IEEE 35th Annual Power Electronics Specialists Conference (IEEE Cat. No.04CH37551), vol. 6, June 2004, pp. 4736-4742 Vol.6.

[10] H. Tao, A. Kotsopoulos, J. L. Duarte, and M. A. M. Hendrix, "Multiinput bidirectional dc-dc converter combining dc-link and magneticcoupling for fuel cell systems," in Fourtieth IAS Annual Meeting. Conference Record of the 2005 Industry Applications Conference, 2005., vol. 3, Oct 2005, pp. 2021-2028 Vol. 3.

[11] Z. Qian, O. Abdel-Rahman, H. Al-Atrash, and I. Batarseh, "Modeling and control of three-port $\mathrm{dc} / \mathrm{dc}$ converter interface for satellite applications," IEEE Transactions on Power Electronics, vol. 25, no. 3, pp. 637-649, March 2010.

[12] N. Zhang, D. Sutanto, and K. M. Muttaqi, "A review of topologies of three-port dc-dc converters for the integration of renewable energy and energy storage system," Renewable and Sustainable Energy Reviews, vol. 56, pp. 388-401, 2016.

[13] Y. Du and D. D.-C. Lu, "Battery-integrated boost converter utilizing distributed mppt configuration for photovoltaic systems," Solar energy, vol. 85, no. 9, pp. 1992-2002, 2011.

[14] F. Kardan, R. Alizadeh, and M. R. Banaei, "A new three input dc/dc converter for hybrid pv/fc/battery applications," IEEE Journal of Emerging and Selected Topics in Power Electronics, vol. 5, no. 4, pp. 1771-1778, Dec 2017.

[15] L. Chien, C. Chen, J. Chen, and Y. Hsieh, "Novel three-port converter with high-voltage gain," IEEE Transactions on Power Electronics, vol. 29, no. 9, pp. 4693-4703, Sept 2014 